7. Reprod. Fert. (1968) 17, 125-137

\title{
MORPHOLOGY, MOTILITY AND FERTILITY OF SPERMATOZOA RECOVERED FROM DIFFERENT AREAS OF LIGATED RABBIT EPIDIDYMIDES
}

\author{
S. K. PAǓFLER AND R. H. FOOTE \\ Tierärztliches Institut der Universität Göttingen, Germany, \\ and Department of Animal Science, Cornell University, Ithaca, New York, U.S.A.
}

(Received 6th October 1967, accepted 22nd April 1968)

Summary. Forty-three males were divided into three experimental groups and ligatures placed unilaterally as follows: (1) on the ductus deferens, (2) on the ductus deferens and corpus epididymidis, and (3) on the ductus deferens, corpus epididymidis and ductuli efferentes. Semen was collected six times a week from all males before ligation and for as long as 12 weeks thereafter.

Spermatozoa transported normally from the caput to the cauda epididymidis in non-ligated controls were characterized by rapid migration of the protoplasmic droplets, a decrease in swollen acrosomes and other abnormalities, an increase in the percentage of motile cells and a striking increase in fertility. Ligation of the ductus deferens only had little effect upon any of these changes. Also, considerable motility and fertility was maintained for 12 weeks following single ligation in contrast to a reduction after 4 weeks in the group with the isolated cauda epididymidis. This suggests that considerable mixing of spermatozoa normally can occur in the cauda. The proportion of abnormal forms, particularly decapitated spermatozoa, increased considerably in the isolated cauda by 8 weeks.

In the isolated caput abnormal spermatozoa increased rapidly and motility decreased. The protoplasmic droplet movement was delayed, as $54 \%$ had droplets on the midpiece after 4 weeks in contrast with $16 \%$ on spermatozoa which migrated normally to the cauda. Severe degeneration and disappearance of spermatozoa followed after 4 weeks, indicating that the caput may have dissolution properties.

Litter size, based on all does inseminated, averaged only 0.5 for caput spermatozoa compared with 5.0 for both caudal and ejaculated spermatozoa. The morphological and fertility data indicate that extrinsic factors as well as intrinsic ones are required for complete development of the fertilizing capacity of rabbit spermatozoa.

\section{INTRODUCTION}

Spermatozoa undergo numerous maturation changes as they migrate through the epididymis. Young (1931) concluded that this maturation was a temporal 
phenomenon in the guinea-pig. However, Redenz (1924) considered epididymal secretions to be of major importance. In the rabbit, Bedford $(1963,1966)$ reported that as the spermatozoa move from the caput to the cauda epididymidis, (a) the length and width of the acrosome decreases, (b) the protoplasmic droplet migrates and often is missing from the spermatozoan tail, and (c) fertility of the spermatozoa is developed. Glover (1962) observed a change in permeability to eosin during transit of epididymal spermatozoa. These changes are generally similar to those reported for the bull and several other species (Branton \& Salisbury, 1947; Nicander, 1958; Amann \& Almquist, 1962). The extent to which these changes depend upon intrinsic and extrinsic factors is not clearly understood.

Studies by Glover $(1960,1962)$ and Gaddum \& Glover (1965), in which rabbit spermatozoa were retained in the caput or corpus epididymidis by means of ligatures, suggested that maturation could take place without the normal migration. In similar experiments, Fulka \& Koefoed-Johnsen (1966) confirmed several of the morphological changes observed by Gaddum \& Glover (1965), but insemination tests revealed that fertility of spermatozoa from the caput epididymidis did not develop fertilizing capacity equivalent to spermatozoa from the cauda epididymidis. Recently Orgebin-Crist (1967a, b) also reported that rabbit spermatozoa do not attain appreciable fertility in the caput epididymidis.

The experiments reported here were designed to clarify the relative importance of temporal and extrinsic factors in the maturation of rabbit spermatozoa as judged by changes in motility, morphology and particularly in live young produced. In order to compartmentalize some of the possible factors involved, use was made of single and multiple ligatures placed unilaterally, with nonligated contralateral sides serving as controls. Ample time was allowed for maturation, based upon normal transport time in the rabbit epididymis (Amann, Koefoed-Johnsen \& Levi, 1965; Orgebin-Crist, 1965; Swierstra \& Foote, 1965).

\section{Animals}

\section{MATERIALS AND METHODS}

Dutch Belted rabbits of known age and history bred in the experimental colony were used. Forty-three sexually mature males were trained to serve the artificial vagina (Bredderman, Foote \& Yassen, 1964). Two semen collections from each male were made on Monday, Wednesday and Friday for at least 4 weeks before the experiments so that each experimental group could be equalized initially on the basis of semen quality. The six/week semen collections were continued throughout the experimental period. One hundred and twenty-one sexually mature females were used for the fertility tests.

\section{Treatments}

Experiment 1 consisted of twelve males divided equally into three sub-groups maintained with ligatures for either 4,8 or 12 weeks. A ligature was placed unilaterally on all males at the proximal portion of the ductus deferens just distal to the cauda epididymidis. The side to be ligated was chosen at random 
and the opposite untreated side served as a control. Two control testes and epididymides from animals in each sub-group were removed at Day 0 , and two each after 4, 8 and 12 weeks, when the ligated sides also were removed from four animals per sub-group.

Experiment 2 consisted of twenty-two males with two ligatures placed unilaterally-one on the middle of the corpus epididymidis and one as in Exp. 1. Thus, spermatozoa in the cauda epididymidis were isolated, and presumably both spermatozoa and fluids from the caput were prevented from entering this area. Testes and epididymides from both control and ligated sides were removed $1,2,3,4,8$ or 12 weeks after ligation.

Experiment 3 consisted of nine males with the two ligatures placed as in Exp. 2 plus a third ligature around the ductuli efferentes. These ligatures served to isolate spermatozoa in the caput epididymidis and in the cauda epididymidis. The males were castrated 1, 4, 8 and 12 weeks after ligation.

All operations were done under ether narcosis. An incision in the scrotum and tunica vaginalis was made large enough to permit small sutures to be placed around the epididymis, being careful to exclude from the ligatures any visible blood vessels that traversed the surface of the epididymis. Gentle manipulation of the testes inside the scrotum assisted in positioning the different sites to be ligated. The scrotal approach was used to avoid the trauma that often accompanies manipulation of the testes into the abdominal cavity when the latter approach is used. Several males, not included in the results, were used to perfect the technique for ligating the ductuli efferentes in Exp. 3 animals. This series of three experiments permitted study of the caput and cauda epididymidis under conditions which allowed spermatozoa and fluid either to pass into both areas, into only the caput epididymidis or into neither segment following ligation.

\section{Measurements}

Ejaculated and epididymal spermatozoa were stained with aniline bluecrystal violet for morphological studies. Epididymal spermatozoa were obtained by cutting the whole caput epididymidis or the central portion of the cauda epididymidis in physiological saline and gently expressing spermatozoa.

One hundred spermatozoa per sample were classified to determine the frequency of protoplasmic droplets and abnormal spermatozoa. Head, head cap, midpiece and tail defects were considered to be important in descending order. Most head cap abnormalities involved swollen acrosomes. Cells with multiple defects were placed in the class given highest priority.

Motility of ejaculated spermatozoa was estimated microscopically each week on a stage incubator following dilution with saline. Motility of spermatozoa obtained from minced epididymides was estimated similarly.

Fertility of the males in Exps. 1 and 2 was tested by insemination of semen collected before ligation. Spermatozoa were recovered from different portions of the epididymis following varying periods of ligation by mincing with iridectomy scissors in $1.0 \mathrm{ml}$ of saline containing penicillin and streptomycin; $0.5 \mathrm{ml}$ of the mixture was inseminated into the anterior portion of the vagina. Sperm concentration in this mixture was counted with the aid of a haemocytometer. This 
count and the estimated percentage of motile spermatozoa were used to calculate the number of motile cells inseminated. Females were injected simultaneously with an ovulating dose of luteinizing hormone and allowed to kindle. Live young were considered to be a more reliable indicator than cleavage of the complete maturation of spermatozoa. The number and sex of the young born were determined within a few hours of birth.

\section{RESULTS}

Experiment 1. Ligature on the ductus deferens

The operation and unilateral ligatures did not appear to interfere with spermatogenesis. Spermatozoa were ejaculated regularly from the control side. On the ligated side they accumulated in and expanded the cauda epididymidis proximal to the ligature. A summary of the results obtained with the twelve males used is shown in Table 1 . Control epididymides showed a similar pattern whether removed $0,4,8$ or 12 weeks after ligation of the contralateral side. Therefore, the twelve males listed under Week 0 in Table 1 represent controls for the twelve males distributed over 4, 8 and 12 weeks. As expected, the proportion of protoplasmic droplets on the spermatozoa was much higher in the caput $(P<0.01)$ than in the cauda epididymidis, and few ejaculated spermatozoa retained the droplet. However, within a location no appreciable change in the position of the droplet was found during the 12-week period of sperm accumulation either in the caput or cauda. Thus, droplet migration did not appear to be altered by the ligature and complete migration did not occur after an extended period of time.

Morphology of ejaculated spermatozoa was similar to spermatozoa found in the cauda epididymidis at the time the ligatures were applied. However, the proportion of decapitated spermatozoa and those with head cap abnormalities in the cauda and in the ductus deferens was high after 12 weeks. These are classified here as abnormal midpieces, since a decapitated spermatozoa had a broken neck and was grouped with the midpiece. The spermatozoa from the caput epididymidis showed a high percentage of abnormals throughout the 12-week period. Many swollen acrosomes were observed, which accounts for the high incidence of abnormal head caps recorded. Many of the sperm cells with abnormal heads also had abnormal tails. These abnormalities were similar to those recently described (Gaddum \& Glover, 1965; Fulka \& Koefoed-Johnsen, 1966), and many represent immature forms (Bedford, 1963) undergoing maturation as spermatozoa pass through the epididymis.

Motility of the spermatozoa in the caput throughout the experiment and in the ductus deferens after 12 weeks was significantly lower $(P<0.01)$ than for caudal or ejaculated spermatozoa. Little change within the caput was noted as spermatozoa probably migrated normally to the cauda. Accumulation in the cauda resulted in a slight decline in motility after 12 weeks $(P<0.05)$.

Fertility of spermatozoa recovered from the caput after all periods was extremely low with twenty-five does producing a total of six young (Table 1). Fertility of caudal spermatozoa was significantly higher $(P<0 \cdot 01)$ and was similar to ejaculated semen. Fertility of spermatozoa stored in the ductus deferens 


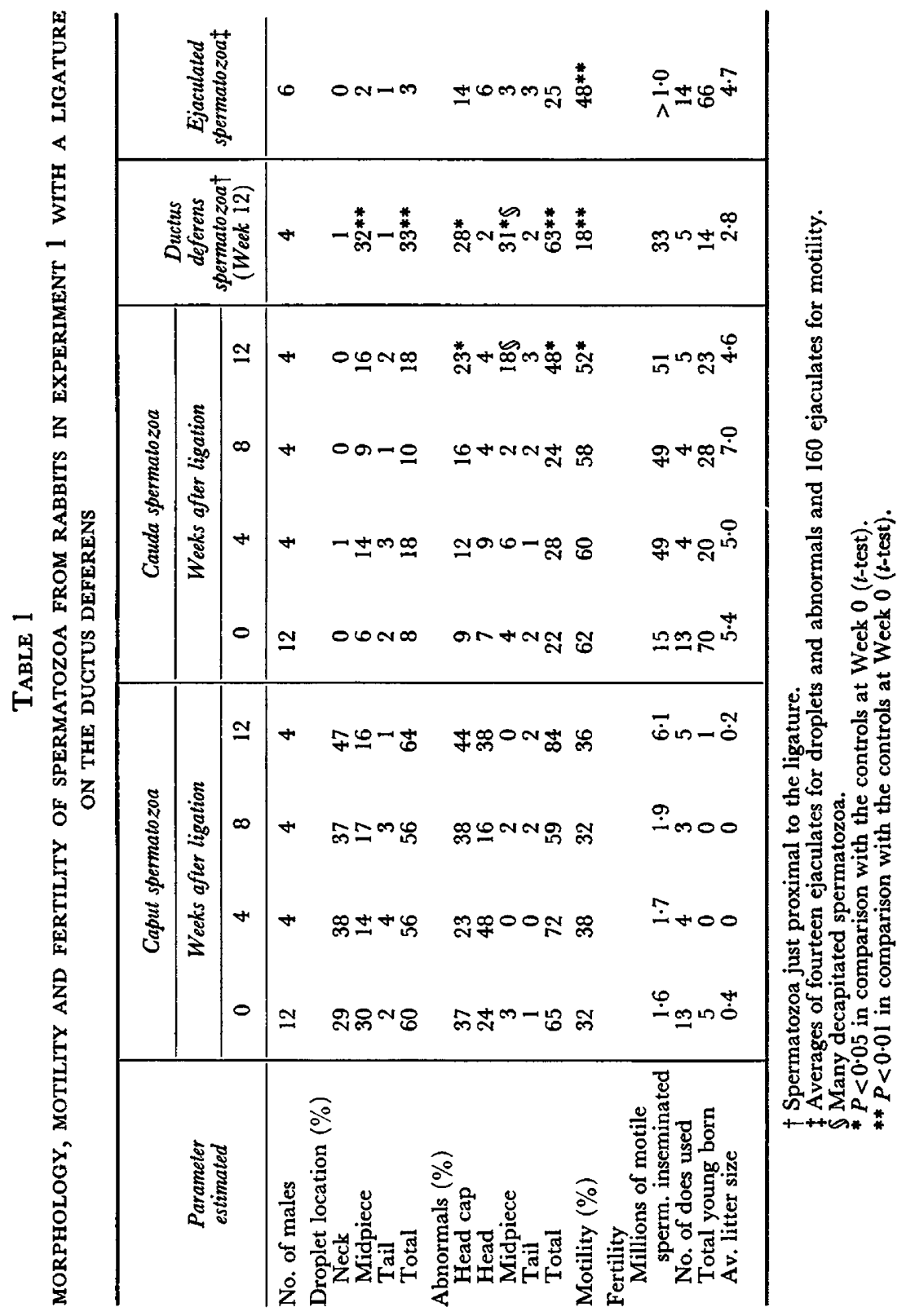


proximal to the ligature was not significantly lower than fertility of ejaculated spermatozoa $(P>0.05)$. These spermatozoa presumably had been in the epididymis for at least 12 weeks. The fact that there was still moderate fertility suggests some mixing with younger spermatozoa. The overall ratio of males to females was $53: 47$, and there was no difference between ligated and control groups.

\section{Experiment 2. Ligatures on the ductus deferens and corpus epididymidis}

The proportion of protoplasmic droplets and their location was similar to those found in Exp. 1 (Table 2). Again the control series is listed under Week 0 . The added ligature on the corpus epididymidis in this experiment was close enough to the testis to produce a more noticeable effect on spermatogenesis. Testicular degeneration was noted within 4 weeks after ligation. After 12 weeks some testes showed almost complete degeneration and others showed some regeneration. Males with continued or renewed spermatogenesis after 8 and 12 weeks showed a higher proportion of droplets located at the base of the head, indicating an influx of newly formed spermatozoa.

Considerable enlargement and oedema of the caput was noted initially, similar to that described by Gaddum \& Glover (1965). After 3 weeks the number of spermatozoa in the caput decreased rapidly, often yielding none or too few to inseminate (Table 2). Most caput spermatozoa were abnormal in the one male with spermatozoa at 4 weeks. The proportion of abnormals decreased at 8 and 12 weeks in rabbits producing new spermatozoa. Spermatozoa in the isolated cauda maintained a low level of abnormal spermatozoa for 3 weeks. Thereafter the percentage of abnormals began to increase (Table 2). Coiled tails and decapitated heads were visible by 4 weeks and the proportion of bent and broken tails continued to increase at 8 and 12 weeks (Pl. 1, Figs. 3 and 4). This difference from Exp. 1 suggested that in the previous experiment mixing with more recently formed normal spermatozoa had occurred.

The percentage of motile spermatozoa in the caput epididymidis decreased during Weeks 2, 3 and 4 as testicular degeneration was detectable, and increased at 8 and 12 weeks associated with some testicular regeneration.

The testicular degeneration and concomitant lack of spermatozoa in the caput of three of the ten males limited the fertility testing that could be done. However, low fertility again was found initially with caput spermatozoa and no fertility was obtained during the 12-week period following ligation. The

\section{EXPLANATION OF PLATE 1}

Photographs of spermatozoa removed from the cauda epididymidis isolated by ligatures on the corpus epididymidis and ductus deferens in Exp. 2. $\times 1160$.

Abbreviations $: \mathrm{h}=$ head, $\mathrm{hc}=$ head cap, $\mathrm{n}=$ neck or midpiece, $\mathrm{p}=$ protoplasmic droplet, $\mathrm{t}=$ tail abnormality.

Figs. 1 and 2. Controls at 0 weeks.

Fig. 3. Eight weeks after ligation.

Fig. 4. Twelve weeks after ligation.

Photographs of spermatozoa removed from the caput epididymidis isolated by ligatures on the ductuli efferentes and corpus epididymidis in Exp. 3. $\times 1160$.

Fic. 5. Controls at 0 weeks. Note protoplasmic droplets.

FIG. 6. Eight weeks after ligation. Note degenerating heads and debris. 
PLATE 1

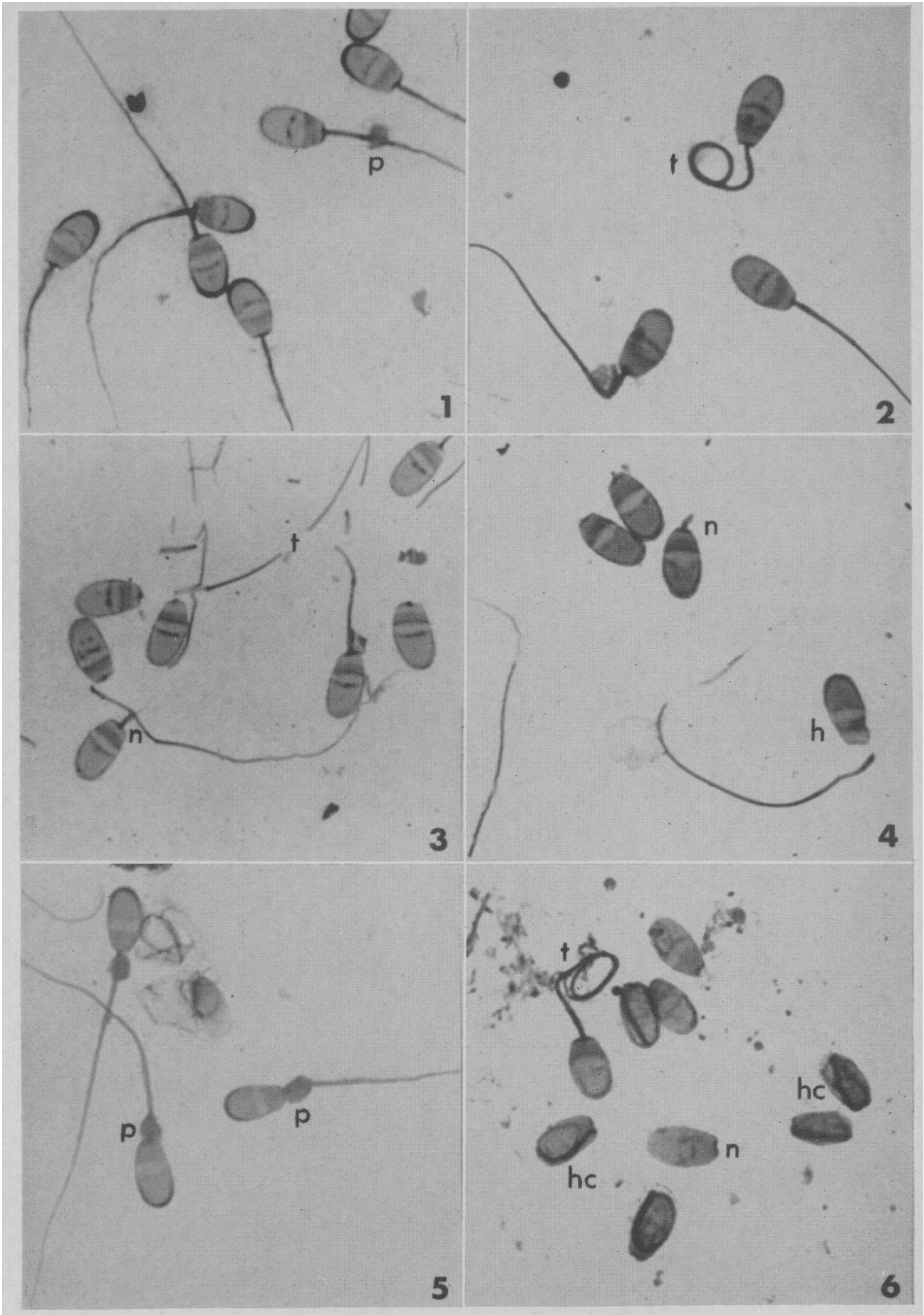

(Facing p. 130) 


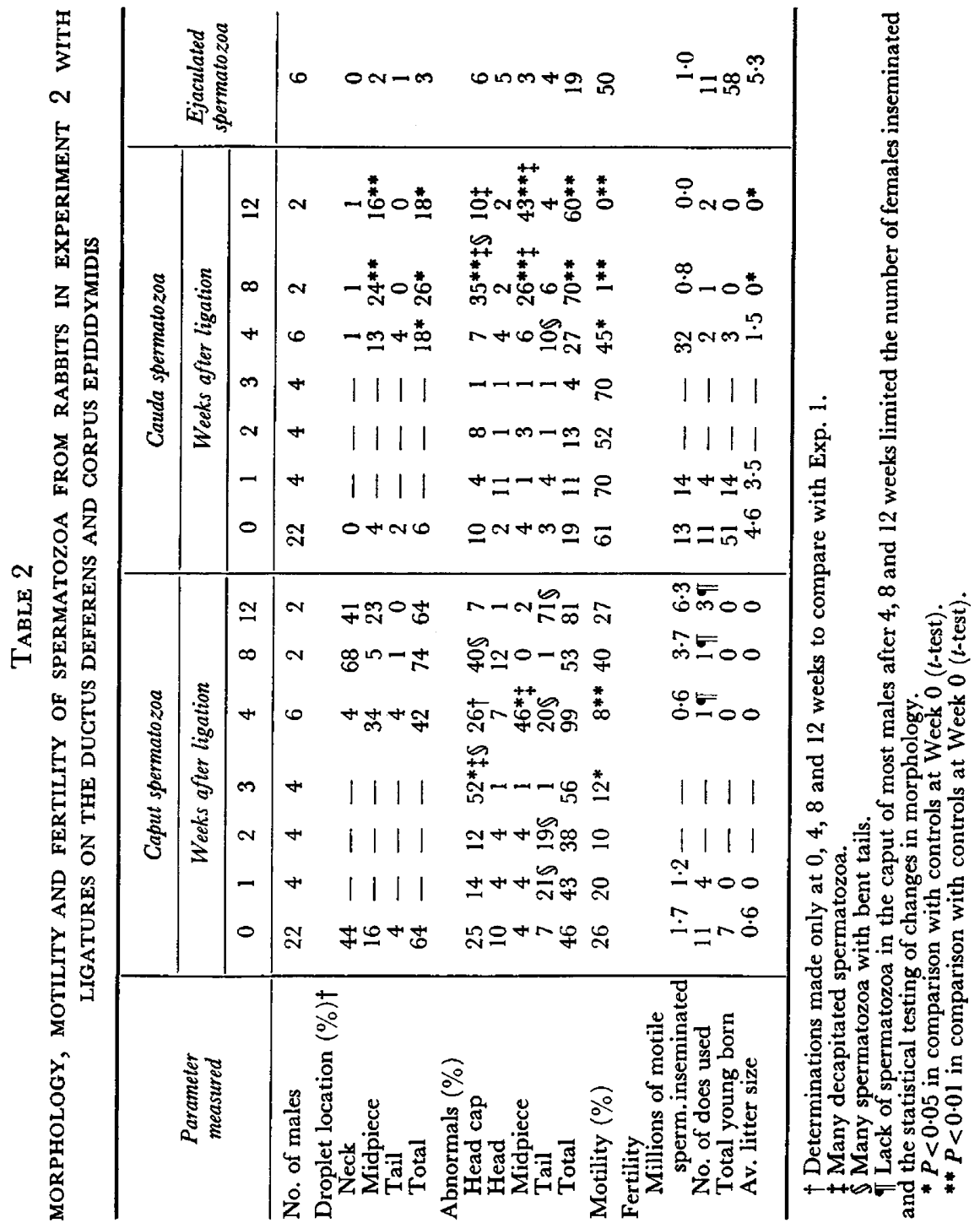




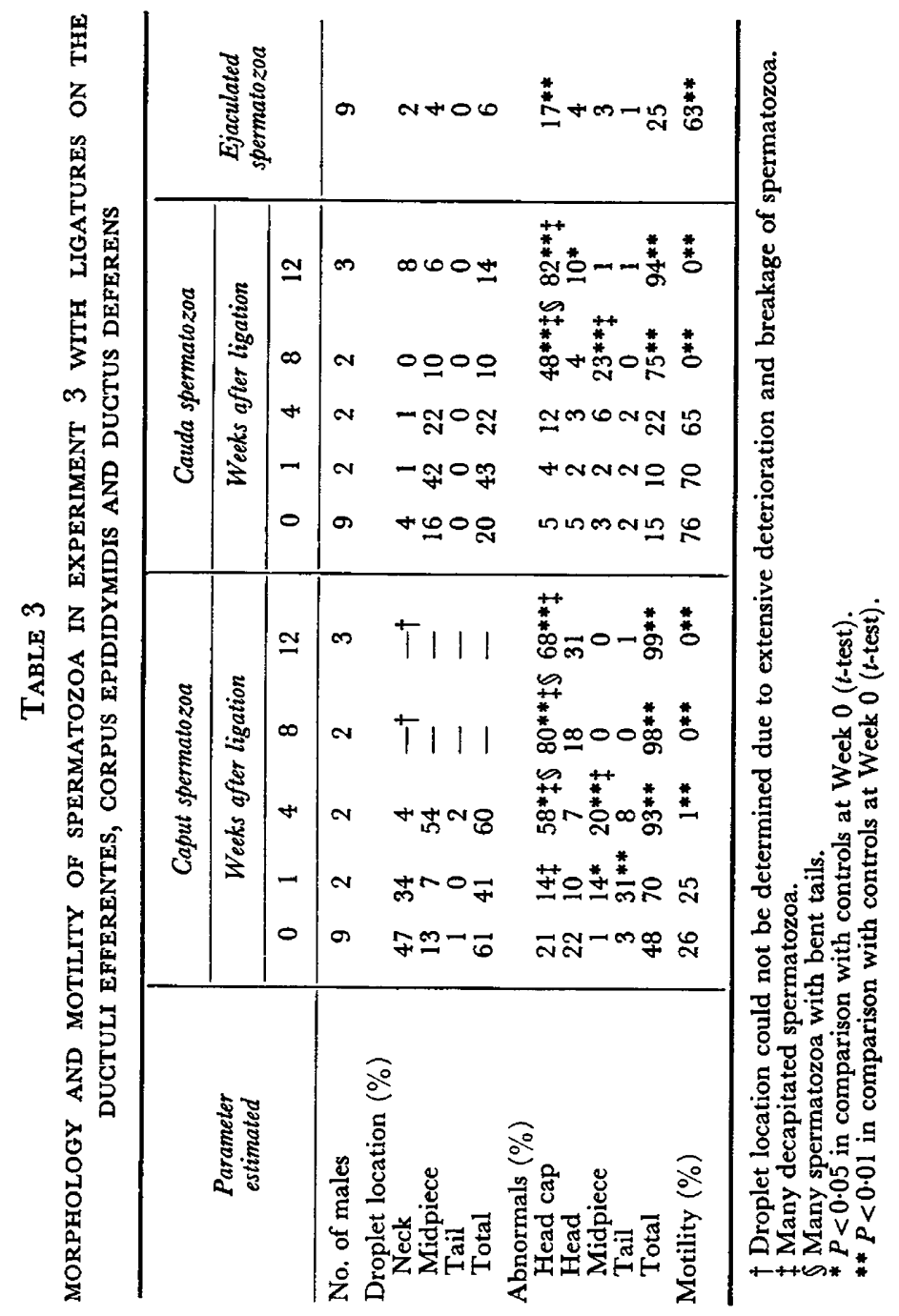


cauda spermatozoa exhibited some motility for 8 weeks, but were fertile up to the 4th week only. This is in contrast to Exp. 1 where new spermatozoa probably mixed with old spermatozoa and young were obtained from cauda spermatozoa throughout the 12-week test period. The sex ratio was the same as in the previous experiment.

Experiment 3. Ligatures on the ductuli efferentes, corpus epididymidis and ductus deferens

Because of the degeneration of many testes when there was a ligature on the corpus epididymidis, it was anticipated that a ligature immediately adjacent to the testes would cause almost immediate and complete testicular degeneration. Only partial degeneration was observed. Results with epididymal spermatozoa are summarized in Table 3.

The most striking change in protoplasmic droplet position was the migration of the droplet from the neck (Pl. 1, Fig. 5) to the midpiece during a 4-week period in the caput. Nearly all spermatozoa were abnormal in the caput after 4 weeks (Table 3). Primarily decapitated heads and debris (Pl. 1, Fig. 6) were found after 8 weeks and the heads were disintegrating after 12 weeks. Most cells had lost their acrosome. The debris may have contained morphologically unrecognizable remains of droplets and spermatozoa as the number of cells recovered decreased with time.

In the cauda there was no evidence of droplet migration but there were differences among rabbits. Increases in head cap and other abnormalities were observed after 8 and 12 weeks.

Motility of spermatozoa in the caput was essentially zero after 4 weeks and was zero in the cauda after 8 weeks (Table 3 ).

\section{DISCUSSION}

The combined data from the three experiments show that spermatozoa recovered from the control cauda epididymidis (Week 0 in Tables 1, 2 and 3) were similar to ejaculated spermatozoa in position of the protoplasmic droplet, $\%$ abnormals, $\%$ motility and fertility, despite some significant differences summarized in Table 4. However, caput and proximal corpus spermatozoa had many more protoplasmic droplets $(P<0 \cdot 01)$, particularly on the neck and midpiece, as reported by others (Amann \& Almquist, 1962; Bedford, 1963; Gaddum \& Glover, 1965; Orgebin-Crist, 1967a). The 28\% head cap abnormalities noted in the caput were primarily swollen acrosomes as reported previously (Bedford, 1963; Gaddum \& Glover, 1965). Since relatively few swollen acrosomes were found in the cauda, this change, along with the migration of protoplasmic droplets, appears to be a component of maturation in the rabbit. The very low fertility of the spermatozoa in the caput and proximal portion of the corpus is in agreement with other work in the rabbit (Bedford, 1965b, 1966; Fulka \& Koefoed-Johnsen, 1966; Orgebin-Crist 1967a, b). It is in contrast to the $33 \%$ pregnancies obtained in guinea-pigs with caput spermatozoa (Young, 1931).

In order to determine whether or not spermatozoa retained in any segment could mature with time alone, spermatozoa in the ligated epididymides were examined after periods from 1 to 12 weeks. Any changes occurring at the same 
rate as when spermatozoa migrate normally could be seen after 1 week (Amann et al., 1965; Orgebin-Crist, 1965; Swierstra \& Foote, 1965), and more slowly occurring changes reflecting maturation and senescence could be seen at the longer intervals. Migration of the protoplasmic droplet in the caput occurred at the normal rate in Exp. 1 (Table 1) probably because the ligature on the ductus deferens had little effect on the caput epididymidis. Therefore, spermatozoa were probably transported at the normal rate. Results in Exp. 2 were equivocal because expected trends in migration in the droplet appeared to be masked by an influx of new spermatozoa from regenerating testes. The desirability of

TABLE 4

SUMMARY OF CONTROLS USED IN EXPERIMENTS 1,2 AND $3 *$

\begin{tabular}{|c|c|c|c|}
\hline $\begin{array}{l}\text { Parameter } \\
\text { estimated }\end{array}$ & $\begin{array}{c}\text { Caput } \\
\text { spermatozoa }\end{array}$ & $\begin{array}{c}\text { Cauda } \\
\text { spermatozoa }\end{array}$ & $\begin{array}{c}\text { Ejaculated } \\
\text { spermatozoa }\end{array}$ \\
\hline No. of males & 24 & 24 & 24 \\
\hline $\begin{array}{l}\text { Droplet location }(\%) \\
\text { Neck } \\
\text { Midpiece } \\
\text { Tail } \\
\text { Total }\end{array}$ & $\begin{array}{r}38^{\mathrm{a}} \\
22^{\mathrm{a}} \\
2^{\mathrm{a}} \\
61^{\mathrm{a}}\end{array}$ & $\begin{array}{r}1^{\mathrm{b}} \\
9^{\mathrm{b}} \\
2^{\mathrm{a}} \\
12^{\mathrm{b}}\end{array}$ & $\begin{array}{l}1^{b} \\
3^{\mathrm{c}} \\
0^{\mathrm{b}} \\
4^{\mathrm{c}}\end{array}$ \\
\hline $\begin{array}{l}\text { Abnormals }(\%) \\
\text { Head cap } \\
\text { Head } \\
\text { Midpiece } \\
\text { Tail } \\
\text { Total }\end{array}$ & $\begin{array}{r}28^{\mathrm{a}} \\
17^{\mathrm{a}} \\
3^{\mathrm{a}} \\
4^{\mathrm{a}} \\
53^{\mathrm{a}}\end{array}$ & $\begin{array}{r}9^{\mathrm{b}} \\
4^{\mathrm{b}} \\
4^{\mathrm{a}} \\
2^{\mathrm{a}} \\
19^{\mathrm{b}}\end{array}$ & $\begin{array}{r}15^{\mathrm{c}} \\
4^{\mathrm{b}} \\
3^{\mathrm{a}} \\
2^{\mathrm{a}} \\
23^{\mathrm{c}}\end{array}$ \\
\hline Motility (\%) & $28^{a}$ & $65^{b}$ & $53^{c}$ \\
\hline $\begin{array}{l}\text { Fertility } \\
\text { No. of females } \\
\text { Total young } \\
\text { Av. litter size }\end{array}$ & $\begin{array}{l}24 \\
12 \\
0 \cdot 5^{a}\end{array}$ & $\begin{array}{c}24 \\
121 \\
5 \cdot 0^{b}\end{array}$ & $\begin{array}{c}25 \\
124 \\
5 \cdot 0^{\mathrm{b}}\end{array}$ \\
\hline
\end{tabular}

* Means on the same line with the same superscript letter are not different and with different letters are significantly different, $P<0 \cdot 05$.

occluding the ductuli efferentes to prevent an influx of young spermatozoa was demonstrated in Exp. 3 (Table 3, Plate 1) where consistent changes in the droplet position were observed. The rate of droplet migration was considerably slower than normal (Nicander, 1958; Orgebin-Crist, 1967a) and than reported by Gaddum \& Glover (1965) following ligation. The failure of spermatozoa to lose their droplets during a 4-week retention period in the caput (Table 3) may be associated with the inability of these spermatozoa to become fully fertile. However, enough lost the droplets to effect fertilization based on the numbers inseminated. After 4 weeks spermatozoa had degenerated (Plate 1, Table 3), preventing further study of droplet migration.

Only a low percentage of cauda spermatozoa had protoplasmic droplets in any of the experiments. There was no decrease over a period of time in any of the ligated caudal segments. Ejaculated spermatozoa from the same animals had fewer droplets, suggesting that most residual droplets were lost during ejaculation.

The proportion of abnormal spermatozoa with swollen acrosomes and coiled 
tails was always high in the caput. Ligation of the ductus deferens had little effect, but a ligature on the corpus caused oedematous swelling of the caput and altered testicular function; in 4 weeks most spermatozoa had disappeared from the caput. The mechanism of resorption is unknown. No phagocytosis of spermatozoa was observed, as reported for abnormal states in man by Phadke (1964). Little resorption is believed to occur in the epididymal lumen of normal rabbits (Nicander, 1958; Bedford, 1965a). Under the conditions of this experiment spermatozoa were destroyed and products removed. The disappearance of spermatozoa from the caput was less pronounced when it was isolated at both ends in Exp. 3. However, the proportion of abnormals rose rapidly within 1 week and at 8 and 12 weeks post-ligation, detached heads and debris characterized the contents of the caput (Plate 1). These changes occur more rapidly than in the bull (Amann \& Almquist, 1962).

Spermatozoa in the cauda epididymidis showed only a small percentage increase in abnormals in Exp. 1, excepting at the site of the ligature on the ductus deferens. With the cauda occluded at both ends in Exps. 2 and 3, decapitated spermatozoa and those with bent tails progressively increased after 4, 8 and 12 weeks (Tables 2 and 3 ; Plate 1 ). Presumably a regular infusion of young normal spermatozoa diluted the effect of older spermatozoa undergoing senescent changes in Exp. 1, but it is possible that protective substances are secreted proximal to the ligature on the corpus and were prevented from reaching the spermatozoa distal to the ligature.

Motility of spermatozoa in the caput was never as vigorous as in the cauda. No increase in motility was found by retaining spermatozoa in the caput for 1 week. However, in other unpublished experiments we have observed an increase in motility as reported by others (Gaddum \& Glover, 1965). Motility in the isolated caput approached zero after 4 weeks as contrasted to excellent motility in the isolated caudal portion at this time (Table 3 ). This suggests that either the cauda provides an environment more favourable for preserving spermatozoan motility, or that cells which have matured while migrating to the cauda are capable of more prolonged survival. The limit of motile life in the cauda would appear to be about 8 weeks (Exp. 2), for it is probable that the motility observed at 12 weeks in the first experiment represented a mixture with younger spermatozoa. The ligature on the corpus also could have caused some damage to caudal spermatozoa, but no evidence of vascular disturbance or necrosis of any sort was found in the ligated epididymides.

The failure of spermatozoa retained in the caput to achieve significant fertilizing capacity argues against the supposition by many that the morphological changes observed represent complete maturation. Only limited fertility was reported by Bedford (1965b), Fulka \& Koefoed-Johnsen (1966) and Orgebin-Crist (1967b) with caput spermatozoa retained by ligatures. Bedford (1966) found that spermatozoa from the caput and proximal portion of the corpus apparently were unable to establish normal contact with the zona pellucida following oviducal insemination, but Orgebin-Crist (1967a) reported that spermatozoa from the caput were able to pass through the utero-tubal junction.

Spermatozoa in the isolated cauda were fertile after 4 weeks but insemination of spermatozoa which were largely immotile after 8 weeks did not produce 
young. This is in agreement with Hammond \& Asdell (1926), who found some rabbits to retain fertility after ageing of spermatozoa in the cauda for 6 weeks. Fertility in Exp. 1 after 12 weeks is again presumed to be due to mixing of spermatozoa.

The fertility of spermatozoa removed from the cauda epididymidis and used for insemination was as high as for ejaculated spermatozoa from the same males (Table 4). Litter size, based on all females inseminated, was equal and high in both groups. Thus, there is no evidence for increased embryo mortality in contrast to results with spermatozoa obtained from the epididymis and inseminated directly into the uterus (Orgebin-Crist, 1967a). In the present experiments sperm suspensions always were treated with antibiotics and placed in the anterior vagina. One possible explanation for the difference is that suspensions of epididymal spermatozoa might contain material that could cause irritation when placed directly into the uterus, thus increasing the pre-implantation losses.

These data indicate that both intrinsic and extrinsic factors are required for rabbit spermatozoa to become fully fertile in the epididymis. Once this state has been reached spermatozoa retain this capacity in the cauda epididymidis for several weeks.

\section{ACKNOWLEDGMENTS}

This investigation was supported in part by Public Health Service Grant GM10263 from the National Institute of General Medical Sciences and by the Population Council, Inc. The authors are grateful to Dr T. Neves, Dr W. Lynn Hunt, Mr R. R. Maurer and Mrs Jean Ames for technical assistance.

\section{REFERENCES}

Amann, R. P. \& Almquist, J. O. (1962) Reproductive capacity of dairy bulls. VII. Morphology of epididymal sperm. 7. Dairy Sci. 45, 1516.

Amann, R. P., Koefoed-Johnsen, H. H. \& Levi, H. (1965) Excretion pattern of labelled spermatozoa and the timing of spermatozoa formation and epididymal transit in rabbits injected with thymidine- ${ }^{3}$ H. F. Reprod. Fert. 10, 169.

BEDFORD, J. M. (1963) Morphological changes in rabbit spermatozoa during passage through the epididymis. 7. Reprod. Fert. 5, 169.

BEDFORD, J. M. (1965a) Changes in fine structure of the rabbit sperm head during passage through the epididymis. F. Anat. 99, 891.

BEDPoRd, J. M. (1965b) Development of the fertilizing ability of spermatozoa in the rabbit epididymis. 7. Reprod. Fert. 10, 286.

BEDford, J. M. (1966) Development of the fertilizing ability of spermatozoa in the epididymis of the rabbit. F. exp. Zool. 163, 319.

Branton, C. \& Salisbury, G. W. (1947) Morphology of spermatozoa from different levels of the reproductive tract of the bull. 7 . Anim. Sci. $6,154$.

Bredderman, P. J., Foote, R. H. \& YAssen, A. M. (1964) An improved artificial vagina for collecting rabbit semen. F. Reprod. Fert. 7, 401.

Fulka, J. \& Koefoed-Johnsen, H. H. (1966) Epididymispassagens indvirkning på spermiernes morfologi og befrugtningsevne. Arsberetn. Inst. Sterilitetsforskn. K. Vet-og Landbohojskole (Kbh.), p. 213.

GADDUM, P. \& Glover, T. D. (1965) Some reactions of rabbit spermatozoa to ligation of the epididymis. 7. Reprod. Fert. 9, 119.

Glover, T. D. (1960) Spermatozoa from the isolated cauda epididymidis of rabbits and some effects of artificial cryptorchidism. 7. Reprod. Fert. 1, 121.

GLover, T. D. (1962) The response of rabbit spermatozoa to artificial cryptorchidism and ligation of the epididymis. F. Endocr. 23, 317. 
Hammond, J. \& Asdell, S. A. (1926) The vitality of the spermatozoa in the male and female reproductive tracts. F. exp. Biol. 4, 155.

Nicander, L. (1958) On the regional histology and cytochemistry of the ductus epididymidis in rabbits. Acta morph. neerl.-scand. 1, 99.

Orgebin-CRIst, M. C. (1965) Passage of spermatozoa labelled with thymidine- ${ }^{3} \mathrm{H}$ through the ductus epididymidis of the rabbit. F. Reprod. Fert. 10, 241.

Orgebin-CRIST, M. C. (1967a) Maturation of spermatozoa in the rabbit epididymis: fertilizing ability and embryonic mortality in does inseminated with epididymal spermatozoa. Annls Biol. anim. Biochim. Biophys. 7, 373.

Orgebin-Crist, M. C. (1967b) Sperm maturation in rabbit epididymis. Nature, Lond. 216, 816.

PhADKe, A. M. (1964) Fate of spermatozoa in cases of obstructive azoospermia and after ligation of vas deferens in man. 7. Reprod. Fert. 7, 1.

Redenz, E. (1924) Versuch einer biologischen Morphologie des Nebenhodens. Arch. mikrosk. Anat. EntwMech. 103, 593.

Swierstra, E. E. \& Foote, R. H. (1965) Duration of spermatogenesis and spermatozoan transport in the rabbit based on cytological changes, DNA synthesis and labeling with tritiated thymidine. Am. F. Anat. 116, 401.

WhITE, W. E. (1933) The duration of fertility and the histological changes in the reproductive organs after ligation of the vasa efferentia in the rat. Proc. R. Soc. Lond. B, 113, 544.

Young, W. G. (1931) A study of the function of the epididymis. III. Functional changes undergone by spermatozoa during their passage through the epididymis and vas deferens in the guinea pig. F. exp. Biol. 8, 151. 